ARTICLE

\title{
Designing zero-dimensional dimer-type all-inorganic perovskites for ultra-fast switching memory
}

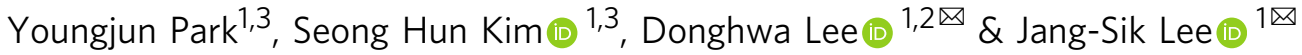

Resistive switching memory that uses halide perovskites (HP) has been considered as nextgeneration storage devices due to low operation voltage and high on/off ratio. However, the memory still faces challenges for stable operation with fast switching speed, which hinders the practical application. Thus, it should be considered from the stage of designing the HP for memory applications. Here, we design the perovskite memory using a high-throughput screening based on first-principles calculations. Total 696 compositions in four different crystal structures are investigated and essential parameters including stability, vacancy formation, and migration are considered as the descriptor. We select dimer- $\mathrm{Cs}_{3} \mathrm{Sb}_{2} \mathrm{l}_{9}$ as an optimal HP for memory; the device that uses dimer- $\mathrm{Cs}_{3} \mathrm{Sb}_{2} \mathrm{l}_{9}$ has ultra-fast switching speed ( $20 \mathrm{~ns}$ ) compared to the device that uses layer- $\mathrm{Cs}_{3} \mathrm{Sb}_{2} \mathrm{l}_{9}$ (>100 ns). The use of leadfree perovskite avoids environmental problems caused by lead in perovskite. These results demonstrate the feasibility to design the memory with ultra-fast switching speed.

\footnotetext{
${ }^{1}$ Department of Materials Science and Engineering, Pohang University of Science and Technology (POSTECH), Pohang 37673, Korea. ${ }^{2}$ Division of Advanced Materials Science, Pohang University of Science and Technology (POSTECH), Pohang, Korea. ${ }^{3}$ These authors contributed equally: Youngjun Park, Seong Hun Kim.凶email: donghwa96@postech.ac.kr; jangsik@postech.ac.kr
} 
T he development of halide perovskites (HPs) has been witnessed in various research areas including electronic and optoelectronic devices because of their excellent properties such as high carrier mobility, high absorption coefficient, and adjustable bandgaps ${ }^{1-7}$. HPs have current-voltage $(I-V)$ hysteresis by migration of ions or defects, which can induce resistive switching behaviors ${ }^{8-10}$. The implementation of the resistive switching behaviors enables various applications such as memory and neuromorphic devices ${ }^{11-14}$. Among various applications, HPs have been evaluated for use in resistive switching memory (RSM) because of high on/off ratio with multilevel data storage, low operation voltage, and forming-free properties ${ }^{15-19}$. These advantages of RSM that uses HP permit implementation as artificial synapses for neuromorphic application ${ }^{11,18}$. However, the RSM still faces challenges for stable operation with fast switching speed. The HP RSM devices can be operated with a limited switching speed, whereas RSM devices that use oxide materials can be operated by using a pulse of subnanosecond $\mathrm{d}^{20-22}$. The switching speed of HP-based RSM is limited even in a small memory cell compared to that of oxide-based memory ${ }^{23,24}$. This limited speed hinders the practical application of HP to RSM despite the advantages of HP as a memory. HP RSM can be operated by formation and rupture of conductive filaments by migration of defects (halide-ion vacancies) ${ }^{25}$. Therefore, to improve the switching speed, the migration of defects in the HP should be understood, and HP in which defects can easily move should be identified. This process should be considered from the stage of designing the HP for RSM.

The use of a computational approach to find an optimal HP for RSM can screen and reduce the number of possible candidate materials, and thereby avoid the human effort, time, and cost of fabricating and testing all possible combinations. The firstprinciples-based approaches have been spotlighted as a powerful tool to accelerate materials researches. In various fields, highthroughput screening methods that use density functional theory (DFT) have been successfully applied ${ }^{26,27}$, but it has not been used to evaluate materials for use in RSM. In addition, the HP RSM devices have been widely developed in three-dimensional (3D) and two-dimensional (2D) layered structures containing lead $(\mathrm{Pb})^{28,29}$, which is environmentally toxic and this component hinders commercialization of devices that use HP. Also, $\mathrm{Pb}$ can induce instability of HPs under air and humidity conditions $^{30,31}$. Tin $(\mathrm{Sn})$ and germanium $(\mathrm{Ge})$ have been evaluated as less-toxic replacements for $\mathrm{Pb}^{32,33}$, but the HPs have low chemical stability because $\mathrm{Sn}^{2+}$ and $\mathrm{Ge}^{2+}$ oxidize easily to $\mathrm{Sn}^{4+}$ and $\mathrm{Ge}^{4+}$ in ambient air and humidity ${ }^{32,34}$. Other $\mathrm{Pb}$-free all-inorganic materials have been evaluated as memory devices $^{35-37}$, but an appropriate $\mathrm{Pb}$-free $\mathrm{HP}$ for stable and highspeed RSM is still required.

In this work, to design a $\mathrm{Pb}$-free HP for RSM with fast switching speed, we combine high-throughput screening and experimental verification. We apply high-throughput screening using first-principles DFT calculations to select promising HPs for RSM. We identify seven candidate HPs considering formation energy for high stability and defect-formation energy for filament formation. Then, of these seven compositions, we calculate the vacancy-migration energy to identify three candidates that are expected to have a fast switching speed, then finally select $\mathrm{Cs}_{3} \mathrm{Sb}_{2} \mathrm{I}_{9}$ with a dimer structure. Experimentally, $\mathrm{Cs}_{3} \mathrm{Sb}_{2} \mathrm{I}_{9}$ can be synthesized in two forms: a dimer structure and a layered structure $^{38,39}$. Our calculation results show that the two structures have similar formation energies and defect-formation energies, but dimer- $\mathrm{Cs}_{3} \mathrm{Sb}_{2} \mathrm{I}_{9}$ is expected to have faster switching speed because the vacancy-migration barrier is lower than that of layer- $\mathrm{Cs}_{3} \mathrm{Sb}_{2} \mathrm{I}_{9}$. To verify our calculation results, we fabricate the RSM device using the dimer- $\mathrm{Cs}_{3} \mathrm{Sb}_{2} \mathrm{I}_{9}$ and compare its resistive switching behavior to RSM using the layer- $\mathrm{Cs}_{3} \mathrm{Sb}_{2} \mathrm{I}_{9}$. Fabricated RSM that uses dimer- $\mathrm{Cs}_{3} \mathrm{Sb}_{2} \mathrm{I}_{9}$ shows a fast switching speed of $\sim 20 \mathrm{~ns}$, whereas the RSM that uses layer- $\mathrm{Cs}_{3} \mathrm{Sb}_{2} \mathrm{I}_{9}$ shows a limited switching speed (>100 ns). These results are consistent with the vacancy-migration energy obtained from the DFT calculations. These studies confirm that the combined method of high-throughput screening and experimental verification can be a promising route to design materials for HP RSM devices.

\section{Results}

Material design by high-throughput screening. To find optimal materials for use in $\mathrm{Pb}$-free $\mathrm{HP}$ for RSM with fast switching speed, we chose four backbone structures: dimer-type $\mathrm{A}_{3} \mathrm{~B}_{2} \mathrm{X}_{9}$, layer-type $A_{3} B_{2} X_{9}$, layer-type $A_{2} B X_{4}$, and cubic $A B X_{3}$ (Fig. 1). For dimer-type $\mathrm{A}_{3} \mathrm{~B}_{2} \mathrm{X}_{9}$ crystal systems, the crystal structure of $\mathrm{Cs}_{3} \mathrm{Bi}_{2} \mathrm{I}_{9}$ with $\mathrm{P}_{3} / \mathrm{mmc}$ space group was used as the backbone structure $^{40}$; it has bioctahedral dimers composed of $\mathrm{B}-\mathrm{X}$ ions. For layer-type $\mathrm{A}_{3} \mathrm{~B}_{2} \mathrm{X}_{9}$ crystal systems, $\mathrm{Cs}_{3} \mathrm{Sb}_{2} \mathrm{Br}_{9}$ crystal structure $(P \overline{3} m 1)$ was considered for the backbone structure; it has cornerconnected bilayer octahedrons ${ }^{41}$. For $\mathrm{A}_{2} \mathrm{BX}_{4}$ crystal systems, the

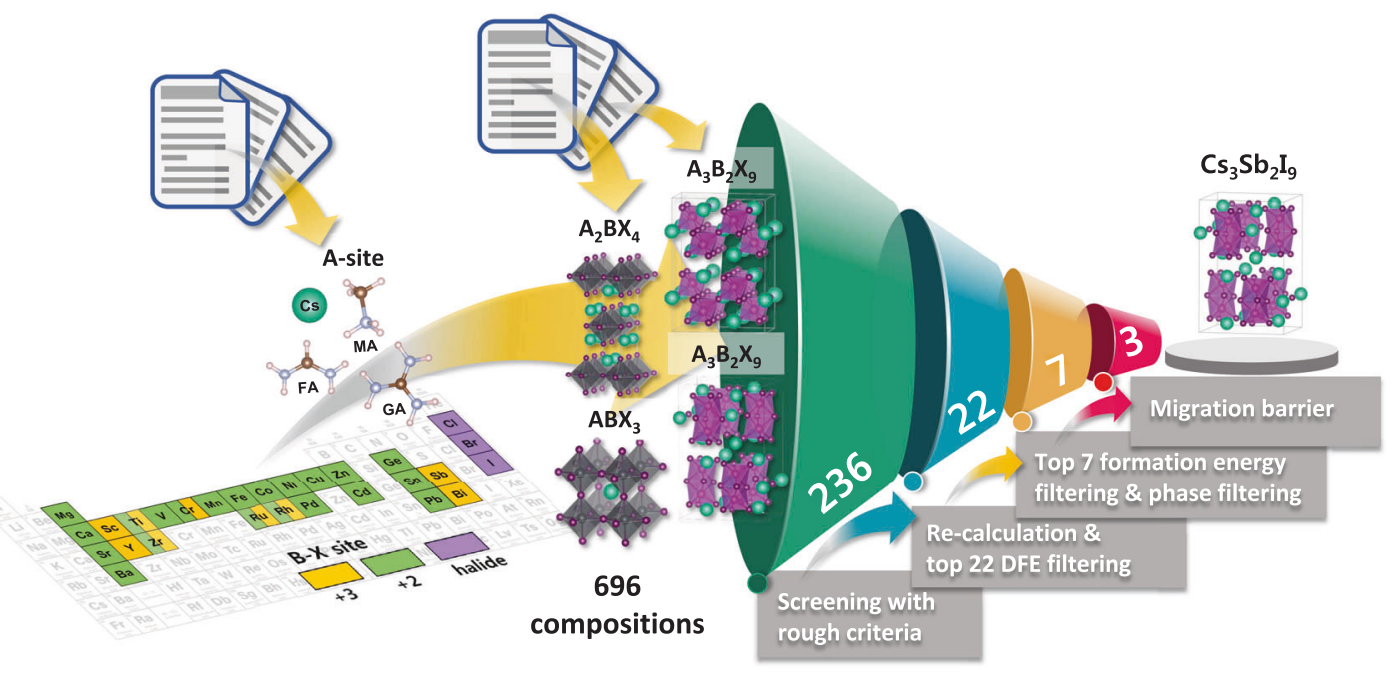

Fig. 1 Four-step screening to identify HP materials for RSM. Four structures that are considered in the four-step high-throughout screening calculation. For trivalent $B$-site cation, dimer-type $A_{3} B_{2} X_{9}$ structure and layer-type $A_{3} B_{2} X_{9}$ structure are used. For divalent $B$-site cation, layered $A_{2} B X_{4}$ structure and cubic $A B X_{3}$ structure are used. Bold numbers in truncated cones indicate the number of compounds that meet the screening criteria. 

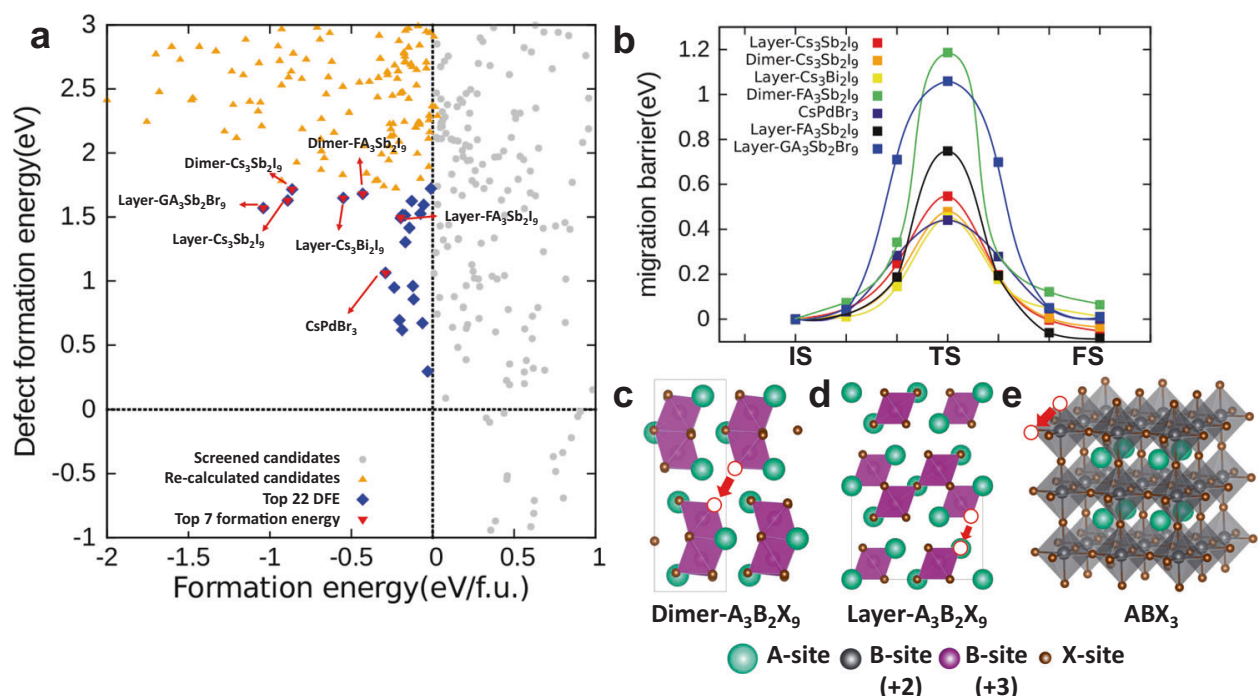

Fig. 2 High-throughput screening for HP RSM. a Formation energies and halide vacancy defect-formation energy of 696 types of candidates. Through four-step screening, the candidates are filtered by 236 possible compositions (yellow), top 22 by defect-formation energy filtering (blue), and top 7 by formation energy and phase filtering (red). The gray circles are excluded candidates due to their positive formation energy. $\mathbf{b} A$ vacancy-migration barrier of top seven candidates (IS initial state, TS transition state, FS final state). Schematic structures of $\mathbf{c}$ dimer- $A_{3} B_{2} X_{9}, \mathbf{d}$ layer- $A_{3} B_{2} X_{9}$, and (e) $A B X_{3}$ (red circle: halide vacancy site, red arrows: vacancy-migration paths). The rectangular boxes in schematic structures are the unit cell of crystal structure.

Ruddlesden-Popper HP structure was considered; it has cornerconnected single-layer octahedra composed of $\mathrm{B}-\mathrm{X}$ ions. Between two kinds of $\mathrm{A}_{2} \mathrm{BX}_{4}$ arrangements (staggered, eclipsed), the staggered arrangement was chosen for the backbone structure because small molecules were prefered to be staggered arrangement ${ }^{42}$. For $\mathrm{ABX}_{3}$ structure, we used $\mathrm{CsPb}_{3}$ crystal structure $(P m \overline{3} m)$, which has been used as a material for RSM ${ }^{43}$. First-principles-based high-throughput screening was performed by changing the composition of four crystal systems. At the Asite, we used four monovalent cations $\left[\mathrm{CH}_{3} \mathrm{NH}_{3}{ }^{+}\left(\mathrm{MA}^{+}\right), \mathrm{HC}\right.$ $\left(\mathrm{NH}_{2}\right)_{2}{ }^{+}\left(\mathrm{FA}^{+}\right), \mathrm{C}\left(\mathrm{NH}_{2}\right)_{3}{ }^{+}\left(\mathrm{GA}^{+}\right)$, and $\left.\mathrm{Cs}^{+}\right)$, which are commonly used in HP. At the B-site cations, 20 divalent cations $\left(\mathrm{Mg}^{2+}, \mathrm{Ca}^{2+}, \mathrm{Sr}^{2+}, \mathrm{Ba}^{2+}, \mathrm{Ti}^{2+}, \mathrm{Zr}^{2+}, \mathrm{Cr}^{2+}, \mathrm{V}^{2+}, \mathrm{Fe}^{2+}, \mathrm{Mn}^{2+}\right.$, $\mathrm{Co}^{2+}, \mathrm{Cu}^{2+}, \mathrm{Ni}^{2+}, \mathrm{Zn}^{2+}, \mathrm{Rh}^{2+}, \mathrm{Pd}^{2+}, \mathrm{Cd}^{2+}, \mathrm{Fe}^{2+}, \mathrm{Sn}^{2+}$, and $\left.\mathrm{Pb}^{2+}\right)$ and 9 trivalent cations $\left(\mathrm{Sc}^{3+}, \mathrm{Ti}^{3+}, \mathrm{Cr}^{3+}, \mathrm{Y}^{3+}, \mathrm{Zr}^{3+}, \mathrm{Ru}^{3+}\right.$, $\mathrm{Rh}^{3+}, \mathrm{Sb}^{3+}$, and $\mathrm{Bi}^{3+}$ ) were chosen. According to the stoichiometry of the crystal systems, trivalent or divalent cations were used in the B-site. At the X-site, we used three halide anions $\left(\mathrm{Cl}^{-}\right.$, $\mathrm{Br}^{-}$, and $\left.\mathrm{I}^{-}\right)$. As a result, we considered a total of 696 combinations (240 compounds for each layer- $\mathrm{A}_{2} \mathrm{BX}_{4}$ and $\mathrm{ABX}_{3}$, and 108 compounds for each dimer- $A_{3} B_{2} X_{9}$ and layer $\left.-A_{3} B_{2} X_{9}\right)$ in this study. To design an optimal HP to apply RSM, we selected formation energy, halide vacancy defect-formation energy, and vacancy-migration barrier as descriptors for high-throughput screening. First, formation energy $\left(E_{\text {form }}\right)\left(\mathrm{eV} \mathrm{f} \mathrm{f.u.}^{-1}\right.$, where f.u. is formula unit) was considered because it could represent material stability ${ }^{44,45}$. $E_{\text {form }}$ of each compound can be calculated as:

$$
E_{\text {form }}=E_{\text {bulk }}^{\text {tot }}-\left(a E_{\mathrm{AX}}^{\text {tot }}+b E_{\mathrm{BX}_{n}}^{\text {tot }}\right)
$$

where $E_{\text {bulk }}^{\text {tot }}$ is the total energy of the A-B-X ternary compound. $E_{\mathrm{AX}}^{\text {tot }}$ is the total energy of precursor $\mathrm{AX}$, and $E_{\mathrm{BX}_{n}}^{\text {tot }}$ is the total energy of precursor $\mathrm{BX}_{n}$. The widely used binary compounds in the synthesis of $\mathrm{HP}$ ( $\mathrm{AX}$ and $\mathrm{BX}_{n}$ ) were chosen as the precursors ${ }^{46,47}$. The subscript $n$ in $\mathrm{BX}_{n}$ was determined by the charge state of $\mathrm{B}$ ion; if it is trivalent, $n=3$ and if it is divalent, $n=2$. The stoichiometry of the A-B-X compound was maintained by appropriately determining $a$ and $b$ : for $\mathrm{A}_{3} \mathrm{~B}_{2} \mathrm{X}_{9}, a=3, b$ $=2$; $\mathrm{ABX}_{3}, a=1, b=1$; and for $\mathrm{A}_{2} \mathrm{BX}_{4}, a=2, b=1$. Second, we used halide vacancy defect-formation energy (DFE $\left.\left[V_{X}\right], e V\right)$ because previous studies showed that it was most correlated with the operation of RSM device ${ }^{48}$. DFE $\left[V_{X}\right]$ can be calculated as

$$
\mathrm{DFE}\left[V_{X}\right]=E_{\text {tot }}\left[V_{X}\right]-E_{\text {bulk }}^{\text {tot }}+\mu_{x}
$$

where $E_{\text {tot }}\left[V_{X}\right]$ is the total energy of the system with single defect $\left(V_{X}\right), E_{\text {bulk }}^{\text {tot }}$ is the total energy of a perfect A-B-X ternary system, and $\mu_{x}$ is the chemical potential of $\mathrm{X}$ anion. Third, we considered the migration barrier of $V_{X}\left(E_{\mathrm{mig}}\left[V_{X}\right]\right)$ as a descriptor for the switching speed of RSM device, because the migration barrier of halide vacancies could affect the switching behavior of RSM device $25,49-51$. We note here that the migration barrier of $V_{X}$ is not the only factor that determines the switching speed of RSM device. Other factors can also affect the switching speed of RSM device. Examples include process-dependent materials characteristics such as defect concentration, morphology, grain size, homogeneity, and device structure ${ }^{52}$. However, the migration barrier of a halide vacancy is one of the main parameters that can affect the operation speed of RSM devices ${ }^{53,54}$, so it can be used to screen candidate materials. In the crystal structures considered in this study, a halide vacancy can follow either an intra-octahedron path or an inter-octahedron path (Supplementary Fig. 1). Additional calculations were performed to identify the rate-limiting migration pathway of $V_{X}$. DFT results predicted that interoctahedron $E_{\mathrm{mig}}\left[V_{X}\right]$ was higher than intra-octahedron $E_{\mathrm{mig}}\left[V_{X}\right]$ (Supplementary Table 1). Thus, we selected the inter-octahedron $E_{\mathrm{mig}}\left[V_{X}\right]$ as the last descriptor.

The high-throughput screening was conducted in four steps. During each screening step, the number of candidate compounds was reduced, and finally we selected one that was expected to be the best for use in RSM. In the first step, to quickly exclude compounds that are unsuitable for RSM, we calculated $E_{\text {form }}$ and DFE $\left[V_{X}\right]$ of 696 compounds with high force criteria $(<0.05 \mathrm{eV} /$ A) for geometry optimization (Fig. 2a, gray circles). Compounds with positive $E_{\text {form }}$ were excluded because they were expected to be dissociated into precursors spontaneously. As a result, we reduced the number of candidate compounds to 236 species (Fig. 2a, orange triangles). In the second step, we recalculated the selected 236 candidates with low force criteria $(<0.01 \mathrm{eV} / \mathrm{A})$ then ranked them from lowest to highest according to DFE $\left[V_{X}\right]$. Since the lower DFE $\left[V_{X}\right]$ leads to the higher $V_{X}$ concentration, it can 
lower the operating voltage of the RSM device ${ }^{55}$. Thus, we chose the 22 compounds that had the lowest DFE [ $\left.V_{X}\right]$ among the 236 compounds. (Fig. 2a, blue diamonds). In the third step, we focused on the thermodynamic stability of candidate compounds. We ranked the recalculation results of 22 compounds from lowest to highest according to $E_{\text {form }}$ to find compounds with high thermodynamic stability. Then, the 10 compounds with low $E_{\text {form }}$ were selected among 22 compounds. Our screening that used DFT was performed for a specific crystal backbone structure, so we further checked whether the chosen compositions had different stable phases with other crystal structures. Among the ten selected compounds, three compounds $\left(\mathrm{Cs}_{2} \mathrm{CuCl}_{4}, \mathrm{CsCuCl}_{3}\right.$, and $\left.\mathrm{Cs}_{2} \mathrm{PdBr}_{4}\right)$ that reported to exist in different crystal structures were also excluded ${ }^{56-59}$. Thus, seven possible compounds were selected for RSM in the third step (Fig. 2a, red down triangles). In the fourth step, we calculated $E_{\mathrm{mig}}\left[V_{X}\right]$ of the remaining compounds to find compounds that had a fast switching speed. Our calculation results predicted that three compounds [dimer$\mathrm{Cs}_{3} \mathrm{Sb}_{2} \mathrm{I}_{9}(0.47 \mathrm{eV})$, layer-Cs $\left.{ }_{3} \mathrm{Bi}_{2} \mathrm{I}_{9}(0.45 \mathrm{eV}), \mathrm{CsPdBr}_{3}(0.44 \mathrm{eV})\right]$ had lower $E_{\text {mig }}\left[V_{X}\right](<0.5 \mathrm{eV})$ than the others (Fig. 2b-e). Among the three selected compounds, the most probable candidate was selected by combining the results of all three descriptors. The three selected compounds showed similar vacancy-migration barriers, so we also compared $E_{\text {form }}$ and DFE $\left[V_{X}\right]$, which could also affect the stability and device performance. Although $\mathrm{CsPdBr}_{3}$ and layer- $\mathrm{Cs}_{3} \mathrm{Bi}_{2} \mathrm{I}_{9}$ showed the low $E_{\text {mig }}$ to migration of halide ion $\left(0.44\right.$ and $0.47 \mathrm{eV}$, respectively), their $E_{\text {form }}$ were higher than the others $\left(\mathrm{CsPdBr}_{3},-0.28 \mathrm{eV} / \mathrm{f}\right.$.u.; and layer$\mathrm{Cs}_{3} \mathrm{Bi}_{2} \mathrm{I}_{9},-0.54 \mathrm{eV} /$ f.u.). Therefore, $\mathrm{CsPdBr}_{3}$ and layer- $\mathrm{Cs}_{3} \mathrm{Bi}_{2} \mathrm{I}_{9}$ may not be able to form a high-quality and reliable RSM device. However, the $E_{\text {form }}$ was much lower in dimer- $\mathrm{Cs}_{3} \mathrm{Sb}_{2} \mathrm{I}_{9}(-0.86$ eV/f.u.) than in layer- $\mathrm{Cs}_{3} \mathrm{Bi}_{2} \mathrm{I}_{9}(-0.43 \mathrm{eV} /$ f.u. $)$. The low $E_{\text {form }}$ may ensure the formation and reliability of the dimer- $\mathrm{Cs}_{3} \mathrm{Sb}_{2} \mathrm{I}_{9} \mathrm{RSM}$ device, so we chose dimer- $\mathrm{Cs}_{3} \mathrm{Sb}_{2} \mathrm{I}_{9}$ as the most probable candidate for RSM device.

Experimental verification. To verify the results of the calculations, we synthesized $\mathrm{Cs}_{3} \mathrm{Sb}_{2} \mathrm{I}_{9}$ with a dimer structure and used it in RSM device. The RSM device consisted of top $\mathrm{Au}$ electrode, bottom indium tin oxide (ITO) electrode, and a sandwiched thinfilm layer of $\mathrm{Cs}_{3} \mathrm{Sb}_{2} \mathrm{I}_{9}$ (Fig. 3a). The dimer- $\mathrm{Cs}_{3} \mathrm{Sb}_{2} \mathrm{I}_{9}$ was deposited by spin-coating process using the antisolvent dripping method ${ }^{39}$. The $\mathrm{Cs}_{3} \mathrm{Sb}_{2} \mathrm{I}_{9}$ was composed of bioctahedral face-sharing $\left[\mathrm{Sb}_{2} \mathrm{I}_{9}\right]^{3-}$ clusters (Fig. 3b). The deposited layer had a uniform thickness of $170 \mathrm{~nm}$ (Fig. 3c) with a dense and closely packed grain (Supplementary Fig. 2a). Atomic force microscopy (AFM) with a scan size of $5 \times 5 \mu \mathrm{m}$ showed that the $\mathrm{Cs}_{3} \mathrm{Sb}_{2} \mathrm{I}_{9}$ had a root mean square (RMS) roughness of $5.32 \mathrm{~nm}$ (Supplementary Fig. 2b, c). Also, we confirmed the grain size of dimer- $\mathrm{Cs}_{3} \mathrm{Sb}_{2} \mathrm{I}_{9}$ film. The average grain size of dimer- $\mathrm{Cs}_{3} \mathrm{Sb}_{2} \mathrm{I}_{9}$ film was $34 \pm 4 \mathrm{~nm}$, as calculated using the ASTM intercept procedure ${ }^{60}$. The crystalline structure of deposited $\mathrm{Cs}_{3} \mathrm{Sb}_{2} \mathrm{I}_{9}$ was investigated by X-ray diffraction (XRD) (Supplementary Fig. 3). The diffraction peaks were matched well with the dimer structure of $\mathrm{Cs}_{3} \mathrm{Sb}_{2} \mathrm{I}_{9}$ described prviously ${ }^{38,39}$. In X-ray photoelectron spectroscopy (XPS) core-level spectra, the Cs $3 d$ spectrum exhibited paired peaks at 738.3 and $724.3 \mathrm{eV}$, the $\mathrm{Sb} 3 d$ spectrum had peaks at 539.1 and $529.8 \mathrm{eV}$, and I $3 d$ showed two peaks at 630.3 and $618.8 \mathrm{eV}$ (Supplementary Fig. 4). These peaks are similar to previous reports for $\mathrm{Cs}_{3} \mathrm{Sb}_{2} \mathrm{I}_{9}$ films ${ }^{61}$.

The electrical characteristics of $\mathrm{Au} /$ dimer- $\mathrm{Cs}_{3} \mathrm{Sb}_{2} \mathrm{I}_{9} / \mathrm{ITO}$ were investigated to confirm the applicability of dimer- $\mathrm{Cs}_{3} \mathrm{Sb}_{2} \mathrm{I}_{9}$ to RSM device. During the measurement, the electrical signal was applied to the $\mathrm{Au}$, and ITO was grounded. When voltage bias was swept in a positive direction, the current level was changed at $1 \mathrm{~V}$, which suggested that the RSM was changed from a high- resistance state (HRS) to a low-resistance state (LRS) (Fig. 3d). When the voltage bias was swept in the negative direction, the LRS was returned to the initial HRS. We plotted cumulative probability distributions in the two resistance states to confirm the reliability of RSM device. The current levels of two states were measured at the read voltage $(0.1 \mathrm{~V})$ during 50 consecutive voltage sweeps $(0 \rightarrow 1 \rightarrow 0 \rightarrow-1 \rightarrow 0 \mathrm{~V})$. The device showed distinguishable HRS and LRS under repeated device operation (Supplementary Fig. 5). We measured data retention properties of LRS and HRS at a read voltage of $0.1 \mathrm{~V}$. Both LRS and HRS remained stable for $5000 \mathrm{~s}$ without degradation (Fig. 3e). We measured the endurance characteristics using AC biases with positive triangular pulses that had a peak voltage of $2 \mathrm{~V}$ for the set process, and negative triangular pulses that had a peak of $-1.6 \mathrm{~V}$ for the reset process. The width of each pulse was fixed at $10 \mu \mathrm{s}$ and the current levels were measured under a read voltage of $0.1 \mathrm{~V}$. The current level at a read voltage increased after the set process, but decreased after the reset process (Supplementary Fig. 6a, b). The device operated stably for 500 cycles (Supplementary Fig. 6c). We also measured device-to-device variation to quantify the reliability of the RSM device. The resistance states of $20 \mathrm{Cs}_{3} \mathrm{Sb}_{2} \mathrm{I}_{9}$ RSM devices were measured at a read voltage. All devices had distinct HRS and LRS (Supplementary Fig. 7). These results indicated that the RSM could operate reliably. The stability of the device based on HPs in ambient air is a problem to be solved and it can be improved by using passivation layers ${ }^{37,62}$

Fast operation is essential for the practical application of RSM devices, so HP RSM devices with fast switching speed should be achieved. To confirm the possibility of fast operation, we measured the switching speed of RSM device using dimer$\mathrm{Cs}_{3} \mathrm{Sb}_{2} \mathrm{I}_{9}$. A voltage pulse with a pulse width of about 20 ns was applied to the device in parallel with the load resistor $(100 \Omega)$ using the pulse generator (Supplementary Fig. 8a). The series resistor of $500 \Omega$ was additionally used to prevent the permanent breakdown of the device for the set process. Before the measurement, we confirmed that the voltage pulse of about $20 \mathrm{~ns}$ was properly applied to the device using the oscilloscope (Supplementary Fig. 8b, c). The switching speed of RSM was obtained by the required pulse width to change the resistance state. The voltage bias was swept from 0 to $0.4 \mathrm{~V}$ before and after pulse application to confirm the change of resistance state depending on the applied pulse. The voltage sweep range was lower than the operation voltage of RSM, and therefore could not affect the change of resistance. As the positive voltage pulse $(6 \mathrm{~V}$, $20 \mathrm{~ns}$ ) was applied to the RSM device, the resistance state was changed from initial HRS to LRS (Fig. 4a). Also, the LRS was recovered to the initial HRS by application of the negative voltage pulse $(-6 \mathrm{~V}, 20 \mathrm{~ns})$ (Fig. 4b). The resistance change depended on the applied pulse width (Supplementary Fig. 9). The resistance change was observed under the pulse with 20 -ns width and the resistance was completely changed when pulse with $40-n$ s width was applied. The resistance changes were plotted depending on the width of the applied pulse for set $(6 \mathrm{~V})$ and reset $(-6 \mathrm{~V})$ processes (Fig. 4c). The current level was also affected by the amplitude of voltage pulse. We applied the positive voltage pulses with different amplitudes $(2,4,6$, and $8 \mathrm{~V})$ with a fixed pulse width of $20 \mathrm{~ns}$ (Supplementary Fig. 10). The change in current level increased as the amplitude of voltage pulse increased. To confirm the reliability of the device, we measured the data retention properties at LRS and HRS. The states were maintained without degradation for $10^{3} \mathrm{~s}$ (Supplementary Fig. 11). Also, we measured the endurance characteristics using nanosecond pulses (Supplementary Fig. 12). Set $(6 \mathrm{~V}, 20 \mathrm{~ns})$ and reset pulses $(-6 \mathrm{~V}$, $20 \mathrm{~ns}$ ) were applied and the current level was measured using the read voltage pulse $(20 \mu \mathrm{s}, 0.1 \mathrm{~V})$. The device was operated stably 

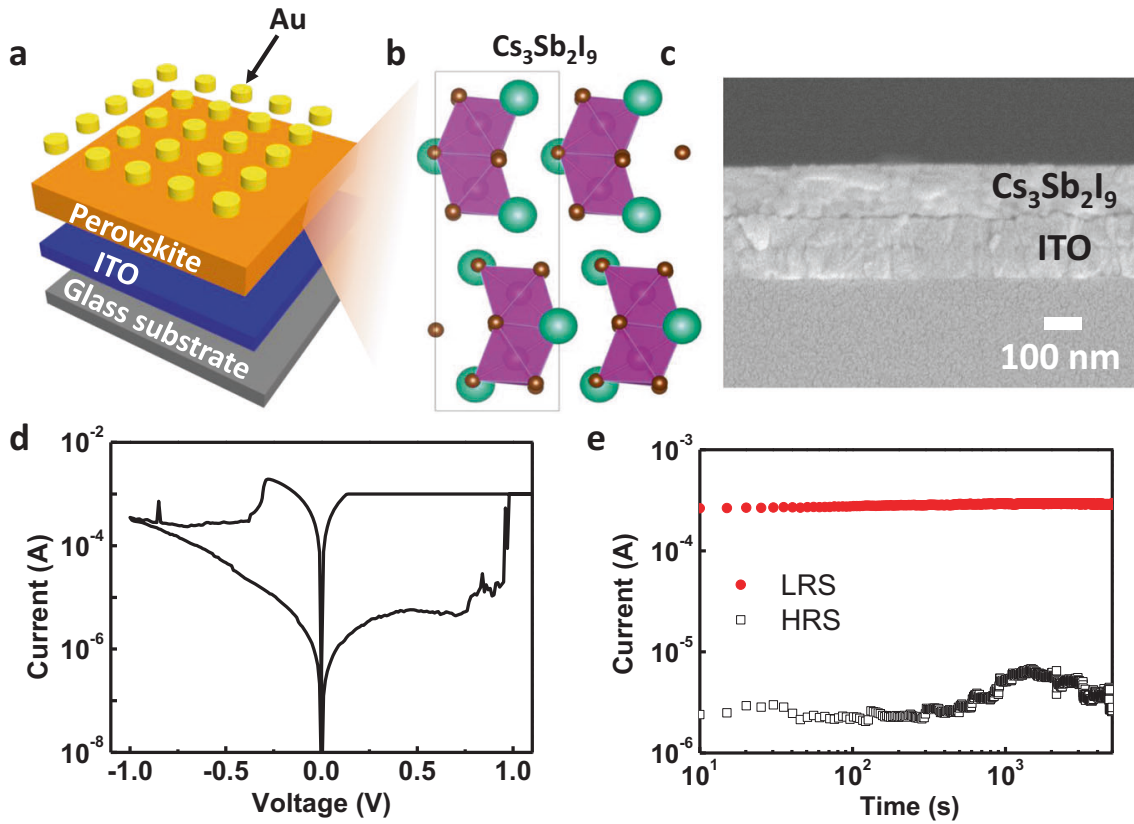

Fig. 3 Schematic illustration and electrical characterstics of HP RSM. a Schematic illustration of RSM device using dimer-C $s_{3} S b_{2} l_{9}$ deposited by a spincoating process. $\mathbf{b}$ Schematic structure of dimer- $\mathrm{Cs}_{3} \mathrm{Sb}_{2} \mathrm{l}_{9}$ (atom colors: $\mathrm{Cs}=$ blue-green; $\mathrm{Sb}=$ purple; I = brown). The rectangular box in schematic structure is the unit cell of crystal structure. c Cross-sectional scanning-electron microscopy (SEM) image of dimer-Cs ${ }_{3} \mathrm{Sb}_{2} l_{9} l_{a y e r}$ on ITO. d I-V characteristics of dimer- $\mathrm{Cs}_{3} \mathrm{Sb}_{2} \mathrm{l}_{9} \mathrm{RSM}$. e Data retention properties of the dimer- $\mathrm{Cs}_{3} \mathrm{Sb}_{2} \mathrm{l}_{9} \mathrm{RSM}$.
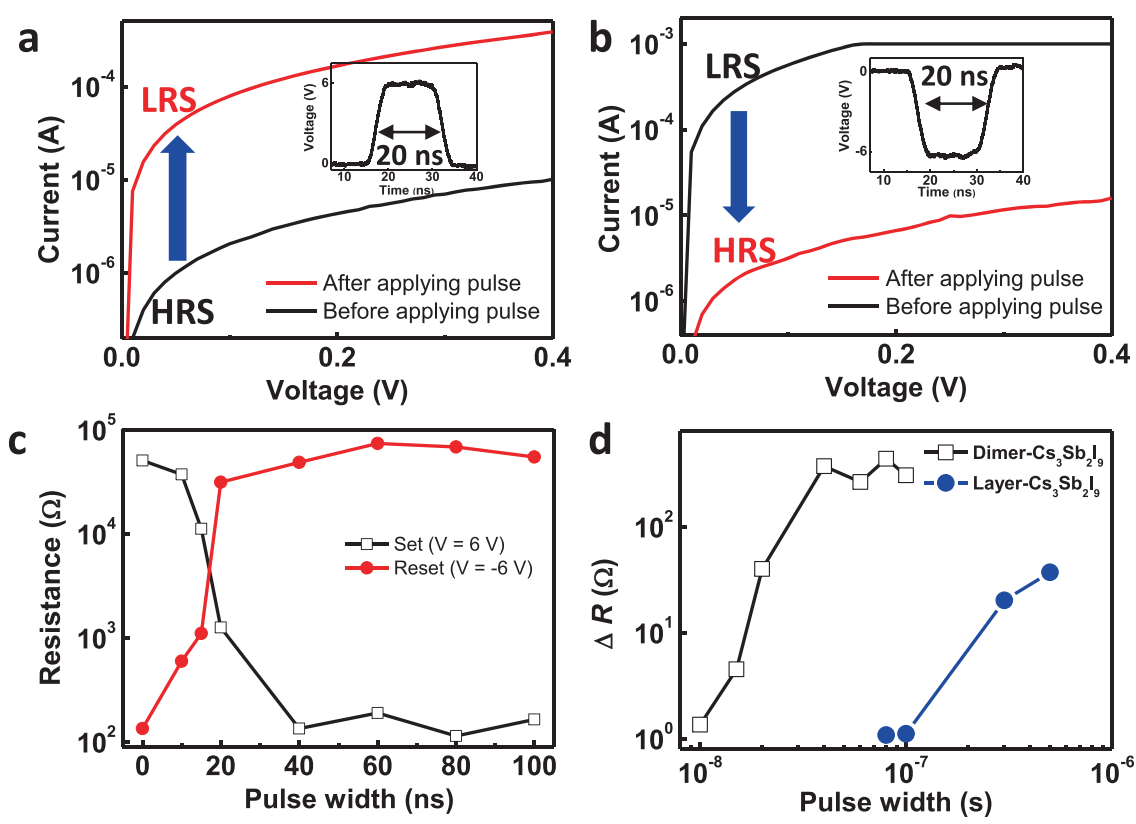

Fig. 4 Switching speed of HP RSM. $I-V$ characteristics of dimer- $-\mathrm{Cs}_{3} \mathrm{Sb}_{2} \mathrm{l}_{9} \mathrm{RSM}$ before and after application of (a) set pulse ( $6 \mathrm{~V}$, $\left.20 \mathrm{~ns}\right)$ and (b) reset pulse $(-6 \mathrm{~V}, 2 \mathrm{~ns})$. c Resistance changes of dimer- $\mathrm{Cs}_{3} \mathrm{Sb}_{2} \mathrm{l}_{9} \mathrm{RSM}$ device with different pulse widths. Amplitudes of applied voltage pulses are fixed for set (6 V) and reset $\left(-6 \mathrm{~V}\right.$ ) processes. $\mathbf{d}$ Resistance changes of dimer- $\mathrm{Cs}_{3} \mathrm{Sb}_{2} \mathrm{l}_{9} \mathrm{RSM}$ and layer- $\mathrm{Cs}_{3} \mathrm{Sb}_{2} \mathrm{l}_{9} \mathrm{RSM}$ devices by application of set pulses ( $6 \mathrm{~V}$ ) with different pulse widths. $\Delta R$ is defined as the ratio between initial resistance and changed resistance after pulse application.

for 50 cycles. These results suggested that the dimer- $\mathrm{Cs}_{3} \mathrm{Sb}_{2} \mathrm{I}_{9}$ RSM device could be operated with a fast switching speed of 20 ns. For comparison, we also measured the switching speed of the RSM device that used layer- $\mathrm{Cs}_{3} \mathrm{Sb}_{2} \mathrm{I}_{9}$. DFT calculations predict that this device will have slower switching speed than the RSM device that uses dimer- $\mathrm{Cs}_{3} \mathrm{Sb}_{2} \mathrm{I}_{9}$, because layer- $\mathrm{Cs}_{3} \mathrm{Sb}_{2} \mathrm{I}_{9}$ has higher $E_{\text {mig }}\left[V_{X}\right](0.57 \mathrm{eV})$ than dimer- $\mathrm{Cs}_{3} \mathrm{Sb}_{2} \mathrm{I}_{9}(0.47 \mathrm{eV})$. To verify this prediction, we deposited the layer- $\mathrm{Cs}_{3} \mathrm{Sb}_{2} \mathrm{I}_{9}$ thin film on ITO. The thickness of layer- $\mathrm{Cs}_{3} \mathrm{Sb}_{2} \mathrm{I}_{9}$ was about $170 \mathrm{~nm}$ (Supplementary Fig. 13a). The film had RMS roughness of $36.1 \mathrm{~nm}$, and average grain size $=290 \pm 15 \mathrm{~nm}$, as calculated using the ASTM intercept procedure (Supplementary Fig. 13b-d) ${ }^{60}$. The XRD of layer- $\mathrm{Cs}_{3} \mathrm{Sb}_{2} \mathrm{I}_{9}$ had high intensity diffraction peak at $25.8^{\circ}$, which is similar to previously reported spectra of $\mathrm{Cs}_{3} \mathrm{Sb}_{2} \mathrm{I}_{9}$ with layer structure (Supplementary Fig. 14) ${ }^{38,39}$. These results indicated that the layer- $\mathrm{Cs}_{3} \mathrm{Sb}_{2} \mathrm{I}_{9}$ film was formed. We fabricated 
an $\mathrm{Au} /$ layer- $\mathrm{Cs}_{3} \mathrm{Sb}_{2} \mathrm{I}_{9} / \mathrm{ITO}$ device, which showed bipolar resistive switching behavior (Supplementary Fig. 15). To compare the switching speed of the devices that used different forms of $\mathrm{Cs}_{3} \mathrm{Sb}_{2} \mathrm{I}_{9}$, we applied voltage pulses $(6 \mathrm{~V})$ with different pulse widths. The resistance change $(\Delta R)$ was defined as the ratio between initial resistance and changed resistance after pulse application. The device that used layer- $\mathrm{Cs}_{3} \mathrm{Sb}_{2} \mathrm{I}_{9} \mathrm{RSM}$ showed little resistance change at pulse width of $100 \mathrm{~ns}$, whereas the device that used dimer- $\mathrm{Cs}_{3} \mathrm{Sb}_{2} \mathrm{I}_{9}$ showed resistance change at pulse width of $20 \mathrm{~ns}$ (Fig. 4d). These observations matched well with our DFT calculation results. In addition, we checked the current changes of layer- $\mathrm{Cs}_{3} \mathrm{Sb}_{2} \mathrm{I}_{9}$ RSM device by the application of voltage pulses $(20 \mathrm{~ns})$ higher than $6 \mathrm{~V}$. When voltage pulses $(6,8$, and $10 \mathrm{~V})$ were applied, there was a slight increase of current levels according to voltages, but the change was not enough for memory operation (Supplementary Fig. 16). These results indicated that the dimer$\mathrm{Cs}_{3} \mathrm{Sb}_{2} \mathrm{I}_{9}$ could be operated with fast switching speed. A comparison between previous HP RSMs and this device is made (Supplementary Table 2).

In summary, we designed the HPs for Pb-free RSM with fast switching speed by using a combined method of first-principlesbased high-throughput screening and experimental verification. A total of 696 compounds with four crystal structures were subjected to a four-step screening process that considered three descriptors $\left(E_{\text {form }}\right.$, DFE $\left[V_{X}\right]$, and $\left.E_{\text {mig }}\left[V_{X}\right]\right)$ to identify candidate materials for RSM. The process identified $\mathrm{Cs}_{3} \mathrm{Sb}_{2} \mathrm{I}_{9}$ with dimer structure as the best compound for Pb-free RSM with fast switching speed. To verify the calculation results, we fabricated RSM device that used the selected dimer structure of $\mathrm{Cs}_{3} \mathrm{Sb}_{2} \mathrm{I}_{9}$. The fabricated RSM was operated with ultra-fast switching speed ( $20 \mathrm{~ns})$ compared to the RSM device that used the layer$\mathrm{Cs}_{3} \mathrm{Sb}_{2} \mathrm{I}_{9}$ (>100 ns); these measurements matched well with DFT calculation results. These results demonstrated the feasibility of reliable $\mathrm{Pb}$-free $\mathrm{HP}$ memory device with ultra-fast switching speed for RSM. We believed that the combined high-throughput screening and experimental verification could be used to design materials for HP RSM devices.

\section{Methods \\ Materials. Dimethylformamide (DMF, 99.8\% purity), cesium iodide (CsI, 99.999\% purity), antimony iodide $\left(\mathrm{SbI}_{3}, 98 \%\right.$, purity), and ITO-coated glass substrates were} purchased from Sigma-Aldrich.

Device fabrication. Precursor solution for dimer- $\mathrm{Cs}_{3} \mathrm{Sb}_{2} \mathrm{I}_{9}$ was prepared by dissolving CsI $(0.75 \mathrm{mmol})$ and $\mathrm{SbI}_{3}(0.5 \mathrm{mmol})$ in DMF $(1 \mathrm{ml})$ solvent overnight at room temperature. Then, the prepared solution was filtered using a polyvinylidene fluoride (PVDF) filter with $0.45-\mu \mathrm{m}$ pore-size. An ITO-coated glass substrate was sequentially cleaned in acetone, isopropyl alcohol (IPA), and distilled water for $15 \mathrm{~min}$ each, then exposed to $\mathrm{UV} / \mathrm{O}_{3}$ for $20 \mathrm{~min}$. Then $\mathrm{Cs}_{3} \mathrm{Sb}_{2} \mathrm{I}_{9}$ thin-film was deposited in a glovebox by using the antisolvent dripping method. The precursor was coated at $2000 \mathrm{rpm}$ for $30 \mathrm{~s}$ with acceleration time of $5 \mathrm{~s}$. IPA as antisolvent was dropped on the rotating substrate after $2-4 \mathrm{~s}$ during the spin-coating process. The deposited film was dried at $100{ }^{\circ} \mathrm{C}$ for $10 \mathrm{~min}$ to remove any residual elements. $\mathrm{Au}$ top electrode with a diameter of $100 \mu \mathrm{m}$ was deposited on $\mathrm{Cs}_{3} \mathrm{Sb}_{2} \mathrm{I}_{9}$ film by thermal evaporation. Layer- $\mathrm{Cs}_{3} \mathrm{Sb}_{2} \mathrm{I}_{9}$ was formed using a mixed solution of CsI $(0.75 \mathrm{mmol}), \mathrm{SbI}_{3}(0.5 \mathrm{mmol})$, and $\mathrm{HCl}(30 \mu \mathrm{l})$ in $\mathrm{DMF}^{39}$. The prepared solution was coated under the same condition as dimer- $\mathrm{Cs}_{3} \mathrm{Sb}_{2} \mathrm{I}_{9}$, except for the dropping time of antisolvent. The antisolvent was dropped on the rotating substrate after $8-10 \mathrm{~s}$, then the film was annealed at $230^{\circ} \mathrm{C}$ for $10 \mathrm{~min}$. The other processes for device fabrication proceeded in the same way as dimer- $\mathrm{Cs}_{3} \mathrm{Sb}_{2} \mathrm{I}_{9}$.

Characterization. The morphology and microstructure of $\mathrm{Cs}_{3} \mathrm{Sb}_{2} \mathrm{I}_{9}$ were measured using a field-emission SEM (JSM 7800, JEOL) and AFM (NX 10, Park systems). The crystal structure of $\mathrm{Cs}_{3} \mathrm{Sb}_{2} \mathrm{I}_{9}$ was determined using XRD (D/MAX-2500, Rigaku). The surface of $\mathrm{Cs}_{3} \mathrm{Sb}_{2} \mathrm{I}_{9}$ was investigated using XPS (ESCA LAB250, Thermo Scientific). The electrical characteristics of the fabricated device were measured using a semiconductor parameter analyzer (4200A-SCS, Keithley). The switching speed was measured using a function generator (33600A, Keysight) and an oscilloscope (TDS 5054, Tektronix). Grain size $(G)$ was calculated as $G=$ $6.643856 \log _{10}\left(P_{L}\right)-3.288$, where $P_{L}$ is the number of intersections of grain boundary per unit length of the test line ${ }^{60} . P_{L}$ was determined as $P_{L}=P_{i} /(L / M)$, where $P_{i}$ is the number of intercepts of test lines, $L$ is the length of test lines, and $M$ is the magnification.

Calculation methodology. We conducted the DFT calculations-based highthroughput screening method to design the optimal HP for RSM. DFT calculations were performed using the projector augmented wave method ${ }^{63}$ with the Perdew-Burke-Ernzerhof functional for exchange and correlation potentials ${ }^{64,65}$, which were implemented in the Vienna Ab-initio Simulation Package (VASP) code 66,67 . To calculate the formation energy of a perovskite structure with combination of compounds, the force convergence criterion in structure optimization was set to be $0.05 \mathrm{eV} / \AA$ at the first step and recalculated as $0.01 \mathrm{eV} / \AA$ at the second step, with kinetic energy cutoff of $500 \mathrm{eV}$. The van der Waals correction by using the DFT-D3 method was utilized to consider the interlayer interactions ${ }^{68}$. The calculations of halide vacancy defect-formation energy were performed with the system size, which did not affect the calculation results ( $8 \mathrm{f}$.u. for $\mathrm{ABX}_{3}$ and $\mathrm{A}_{2} \mathrm{BX}_{4}$, and 2 f.u. for dimer- $A_{3} B_{2} X_{9}$ and layer- $A_{3} B_{2} X_{9}$ ). Gamma centered Monkhorst-Pack $k$-point sampling was used to obtain the relaxed structures $(2 \times 2 \times 2$ grids for $\mathrm{A}_{2} \mathrm{BX}_{4}, \mathrm{ABX}_{3}$, and dimer- $\mathrm{A}_{3} \mathrm{~B}_{2} \mathrm{X}_{9} ; 2 \times 2 \times 1$ grids for layer- $\left.\mathrm{A}_{3} \mathrm{~B}_{2} \mathrm{X}_{9}\right)^{69}$. To calculate the migration energy barrier of halide vacancy defect, the nudged elastic band (NEB) method was utilized in the last $\operatorname{step}^{70}$. The NEB method considered a $2 \times$ $2 \times 2$ supercell for $\mathrm{ABX}_{3}$, and $1 \times 2 \times 1$ supercell for both dimer- and layer- $\mathrm{A}_{3} \mathrm{~B}_{2} \mathrm{X}_{9}$

\section{Data availability}

The data that support the findings of this study are available from the corresponding author upon reasonable request.

Received: 25 February 2021; Accepted: 21 May 2021; Published online: 10 June 2021

\section{References}

1. Xing, G. et al. Long-range balanced electron- and hole-transport lengths in organic-inorganic $\mathrm{CH}_{3} \mathrm{NH}_{3} \mathrm{PbI}_{3}$. Science 342, 344-347 (2013).

2. Grätzel, M. The light and shade of perovskite solar cells. Nat. Mater. 13, 838-842 (2014).

3. Blancon, J.-C., Even, J., Stoumpos, C. C., Kanatzidis, M. G. \& Mohite, A. D. Semiconductor physics of organic-inorganic 2D halide perovskites. Nat. Nanotechnol. 15, 969-985 (2020).

4. Jiang, Q. et al. Surface passivation of perovskite film for efficient solar cells. Nat. Photon. 13, 460-466 (2019).

5. Zhao, B. et al. Efficient light-emitting diodes from mixed-dimensional perovskites on a fluoride interface. Nat. Electron. 3, 704-710 (2020).

6. Yin, W.-J., Shi, T. \& Yan, Y. Unique properties of halide perovskites as possible origins of the superior solar cell performance. Adv. Mater. 26, 4653-4658 (2014).

7. Wehrenfennig, C., Eperon, G. E., Johnston, M. B., Snaith, H. J. \& Herz, L. M High charge carrier mobilities and lifetimes in organolead trihalide perovskites. Adv. Mater. 26, 1584-1589 (2014).

8. Meloni, S. et al. Ionic polarization-induced current-voltage hysteresis in $\mathrm{CH}_{3} \mathrm{NH}_{3} \mathrm{PbX}_{3}$ perovskite solar cells. Nat. Commun. 7, 10334 (2016).

9. Gu, C. \& Lee, J.-S. Flexible hybrid organic-inorganic perovskite memory. ACS Nano 10, 5413-5418 (2016).

10. Yoo, E. J. et al. Resistive switching behavior in organic-inorganic hybrid $\mathrm{CH}_{3} \mathrm{NH}_{3} \mathrm{PbI}_{3-\mathrm{x}} \mathrm{Cl}_{\mathrm{x}}$ perovskite for resistive random access memory devices. Adv. Mater. 27, 6170-6175 (2015).

11. $\mathrm{Xu}, \mathrm{W}$. et al. Organometal halide perovskite artificial synapses. Adv. Mater. 28, 5916-5922 (2016).

12. Choi, S. et al. SiGe epitaxial memory for neuromorphic computing with reproducible high performance based on engineered dislocations. Nat. Mater. 17, 335-340 (2018).

13. Wang, Z. et al. Resistive switching materials for information processing. Nat. Rev. Mater. 5, 173-195 (2020).

14. Pan, F., Gao, S., Chen, C., Song, C. \& Zeng, F. Recent progress in resistive random access memories: materials, switching mechanisms, and performance. Mater. Sci. Eng. R.-Rep. 83, 1-59 (2014).

15. Seo, J.-Y. et al. Wafer-scale reliable switching memory based on 2-dimensional layered organic-inorganic halide perovskite. Nanoscale 9, 15278-15285 (2017).

16. Kim, H. et al. Quasi-2D halide perovskites for resistive switching devices with on/off ratios above 109. NPG Asia Mater. 12, 21 (2020).

17. Kim, S.-Y., Yang, J.-M., Choi, E.-S. \& Park, N.-G. Layered $\left(\mathrm{C}_{6} \mathrm{H}_{5} \mathrm{CH}_{2} \mathrm{NH}_{3}\right)_{2} \mathrm{CuBr}_{4}$ perovskite for multilevel storage resistive switching memory. Adv. Funct. Mater. 30, 2002653 (2020).

18. Yang, J.-M. et al. Perovskite-related $\left(\mathrm{CH}_{3} \mathrm{NH}_{3}\right)_{3} \mathrm{Sb}_{2} \mathrm{Br}_{9}$ for forming-free memristor and low-energy-consuming neuromorphic computing. Nanoscale 11, 6453-6461 (2019). 
19. Wang, Y. et al. Synergies of electrochemical metallization and valance change in all-inorganic perovskite quantum dots for resistive switching. Adv. Mater. 30, 1800327 (2018).

20. Hwang, B. \& Lee, J.-S. Lead-free, air-stable hybrid organic-inorganic perovskite resistive switching memory with ultrafast switching and multilevel data storage. Nanoscale 10, 8578-8584 (2018).

21. He, Y. et al. Impact of chemical doping on resistive switching behavior in zirconium-doped $\mathrm{CH}_{3} \mathrm{NH}_{3} \mathrm{PbI}_{3}$ based RRAM. Org. Electron. 68, 230-235 (2019).

22. Torrezan, A. C., Strachan, J. P., Medeiros-Ribeiro, G. \& Williams, R. S. Subnanosecond switching of a tantalum oxide memristor. Nanotechnology 22, 485203 (2011)

23. Hwang, B. \& Lee, J.-S. A strategy to design high-density nanoscale devices utilizing vapor deposition of metal halide perovskite materials. Adv. Mater. 29, 1701048 (2017).

24. Wang, Z. Q. et al. Performance improvement of resistive switching memory achieved by enhancing local-electric-field near electromigrated Agnanoclusters. Nanoscale 5, 4490-4494 (2013).

25. Zhu, X., Lee, J. \& Lu, W. D. Iodine vacancy redistribution in organic-inorganic halide perovskite films and resistive switching effects. Adv. Mater. 29, 1700527 (2017).

26. Borodin, O., Olguin, M., Spear, C. E., Leiter, K. W. \& Knap, J. Towards high throughput screening of electrochemical stability of battery electrolytes. Nanotechnology 26, 354003 (2015).

27. Yu, L. \& Zunger, A. Identification of potential photovoltaic absorbers based on first-principles spectroscopic screening of materials. Phys. Rev. Lett. 108, 068701 (2012).

28. Younis, A. et al. Enhancing resistive switching performance and ambient stability of hybrid perovskite single crystals via embedding colloidal quantum dots. Adv. Funct. Mater. 30, 2002948 (2020).

29. Xia, F. et al. Improved performance of $\mathrm{CH}_{3} \mathrm{NH}_{3} \mathrm{PbI}_{3-\mathrm{x}} \mathrm{Cl}_{\mathrm{x}}$ resistive switching memory by assembling 2D/3D perovskite heterostructures. ACS Appl. Mater. Interfaces 12, 15439-15445 (2020).

30. Christians, J. A., Miranda Herrera, P. A. \& Kamat, P. V. Transformation of the excited state and photovoltaic efficiency of $\mathrm{CH}_{3} \mathrm{NH}_{3} \mathrm{PbI}_{3}$ perovskite upon controlled exposure to humidified air. J. Am. Chem. Soc. 137, 1530-1538 (2015).

31. Leguy, A. M. A. et al. Reversible hydration of $\mathrm{CH}_{3} \mathrm{NH}_{3} \mathrm{PbI}_{3}$ in films, single crystals, and solar cells. Chem. Mater. 27, 3397-3407 (2015).

32. Noel, N. K. et al. Lead-free organic-inorganic tin halide perovskites for photovoltaic applications. Energy Environ. Sci. 7, 3061-3068 (2014)

33. Sun, P.-P., Li, Q.-S., Yang, L.-N. \& Li, Z.-S. Theoretical insights into a potential lead-free hybrid perovskite: substituting $\mathrm{Pb}^{2+}$ with $\mathrm{Ge}^{2+}$. Nanoscale 8, 1503-1512 (2016)

34. Jin, Z. X. et al. A critical review on bismuth and antimony halide based perovskites and their derivatives for photovoltaic applications: recent advances and challenges. J. Mater. Chem. A 8, 16166-16188 (2020).

35. Zeng, F. et al. Opportunity of lead-free all-inorganic $\mathrm{Cs}_{3} \mathrm{Cu}_{2} \mathrm{I}_{5}$ perovskite film for memristor and neuromorphic computing applications. ACS Appl. Mater. Interfaces 12, 23094-23101 (2020).

36. Xiong, Z. et al. Air-stable lead-free perovskite thin film based on $\mathrm{CsBi}_{3} \mathrm{I}_{10}$ and its application in resistive switching devices. ACS Appl. Mater. Interfaces 11, 30037-30044 (2019).

37. Han, J. S. et al. Lead-free all-inorganic cesium tin iodide perovskite for filamentary and interface-type resistive switching toward environmentfriendly and temperature-tolerant nonvolatile memories. ACS Appl. Mater. Interfaces 11, 8155-8163 (2019).

38. Saparov, B. et al. Thin-film preparation and characterization of $\mathrm{Cs}_{3} \mathrm{Sb}_{2} \mathrm{I}_{9}$ : a lead-free layered perovskite semiconductor. Chem. Mater. 27, 5622-5632 (2015).

39. Umar, F. et al. Dimensionality controlling of $\mathrm{Cs}_{3} \mathrm{Sb}_{2} \mathrm{I}_{9}$ for efficient allinorganic planar thin film solar cells by $\mathrm{HCl}$-assisted solution method. $A d v$. Optical Mater. 7, 1801368 (2019).

40. $\mathrm{Hu}, \mathrm{Y}$. et al. Ultrathin $\mathrm{Cs}_{3} \mathrm{Bi}_{2} \mathrm{I}_{9}$ nanosheets as an electronic memory material for flexible memristors. Adv. Mater. Interfaces 4, 1700131 (2017).

41. Mao, J.-Y. et al. Lead-free monocrystalline perovskite resistive switching device for temporal information processing. Nano Energy 71, 104616 (2020).

42. Zhang, L. et al. Bright free exciton electroluminescence from Mn-doped twodimensional layered perovskites. J. Phys. Chem. Lett. 10, 3171-3175 (2019).

43. Han, J. S. et al. Air-stable cesium lead iodide perovskite for ultra-low operating voltage resistive switching. Adv. Funct. Mater. 28, 1705783 (2018).

44. Castelli, I. E. et al. Computational screening of perovskite metal oxides for optimal solar light capture. Energy Environ. Sci. 5, 5814-5819 (2012).

45. Curtarolo, S. et al. The high-throughput highway to computational materials design. Nat. Mater. 12, 191-201 (2013)

46. Wang, K. H. et al. Large-scale synthesis of highly luminescent perovskiterelated $\mathrm{CsPb}_{2} \mathrm{Br}_{5}$ nanoplatelets and their fast anion exchange. Angew. Chem. Int. Ed. 55, 8328-8332 (2016).
47. Liu, M. et al. Unveiling solvent-related effect on phase transformations in $\mathrm{CsBr}-\mathrm{PbBr}_{2}$ system: coordination and ratio of precursors. Chem. Mater. 30 5846-5852 (2018)

48. Jung, J. H., Kim, S. H., Park, Y., Lee, D. \& Lee, J.-S. Metal-halide perovskite design for next-generation memories: first-principles screening and experimental verification. Adv. Sci. 7, 2001367 (2020).

49. Hur, J. H. et al. Modeling for multilevel switching in oxide-based bipolar resistive memory. Nanotechnology 23, 225702 (2012).

50. Menzel, S., von Witzleben, M., Havel, V. \& Böttger, U. The ultimate switching speed limit of redox-based resistive switching devices. Faraday Discuss. 213, 197-213 (2019).

51. Hwang, B., Gu, C., Lee, D. \& Lee, J.-S. Effect of halide-mixing on the switching behaviors of organic-inorganic hybrid perovskite memory. Sci. Rep. 7, 43794 (2017).

52. Xiao, Z. et al. Giant switchable photovoltaic effect in organometal trihalide perovskite devices. Nat. Mater. 14, 193-198 (2015).

53. Siegel, S. et al. Trade-off between data retention and switching speed in resistive switching reram devices. Adv. Electron. Mater. 7, 2000815 (2021).

54. Lee, J. S., Lee, S. \& Noh, T. W. Resistive switching phenomena: a review of statistical physics approaches. Appl. Phys. Rev. 2, 031303 (2015).

55. Ge, N.-N., Gong, C.-H., Yuan, X.-C., Zeng, H.-Z. \& Wei, X.-H. Effect of Mn doping on electroforming and threshold voltages of bipolar resistive switching in $\mathrm{Al} / \mathrm{Mn}: \mathrm{NiO} / \mathrm{ITO}$. RSC Adv. 8, 29499-29504 (2018).

56. Nakagawa, N. et al. Magneto-chiral dichroism of $\mathrm{CsCuCl}_{3}$. Phys. Rev. B 96, 121102 (2017).

57. Booker, E. P. et al. Synthesis, characterization, and morphological control of $\mathrm{Cs}_{2} \mathrm{CuCl}_{4}$ nanocrystals. J. Phys. Chem. C. 123, 16951-16956 (2019).

58. Perry, C., Athans, D., Young, E., Durig, J. \& Mitchell, B. Far infrared spectra of palladium compounds-III tetrahalo, tetraammine and dihalodiammine complexes] of palladium (II). Spectrochim. Acta A 23, 1137-1147 (1967).

59. Ni, D. et al. A monoclinic form of anhydrous $\mathrm{Cs}_{2} \mathrm{PdCl}_{4}$. Solid State Sci. 87, 118-123 (2019).

60. Nie, W. et al. High-efficiency solution-processed perovskite solar cells with millimeter-scale grains. Science 347, 522-525 (2015).

61. Boopathi, K. M. et al. Solution-processable antimony-based light-absorbing materials beyond lead halide perovskites. J. Mater. Chem. A 5, 20843-20850 (2017).

62. Hwang, B. \& Lee, J.-S. Hybrid organic-inorganic perovskite memory with long-term stability in air. Sci. Rep. 7, 673 (2017).

63. Blöchl, P. E. Projector augmented-wave method. Phys. Rev. B 50, 17953-17979 (1994).

64. Perdew, J. P., Burke, K. \& Ernzerhof, M. Generalized gradient approximation made simple. Phys. Rev. Lett. 77, 3865-3868 (1996).

65. Perdew, J. P., Burke, K. \& Wang, Y. Generalized gradient approximation for the exchange-correlation hole of a many-electron system. Phys. Rev. B 57, 16533-16539 (1996).

66. Fuchs, M. \& Scheffler, M. Ab initio pseudopotentials for electronic structure calculations of poly-atomic systems using density-functional theory. Comput. Phys. Commun. 119, 67-98 (1999).

67. Kresse, G. \& Furthmüller, J. Efficient iterative schemes for ab initio total-energy calculations using a plane-wave basis set. Phys. Rev. B 54, 11169-11186 (1996).

68. Grimme, S., Antony, J., Ehrlich, S. \& Krieg, H. A consistent and accurate ab initio parametrization of density functional dispersion correction (DFT-D) for the 94 elements H-pu. J. Chem. Phys. 132, 154104 (2010).

69. Monkhorst, H. J. \& Pack, J. D. Special points for brillouin-zone integrations Phys. Rev. B 13, 5188-5192 (1976).

70. Henkelman, G., Uberuaga, B. P. \& Jónsson, H. A climbing image nudged elastic band method for finding saddle points and minimum energy paths. $J$. Chem. Phys. 113, 9901-9904 (2000).

\section{Acknowledgements}

This work was also supported by National Research Foundation of Korea (NRF2016M3D1A1027665 and 2019R1A2C2084114). This work was also supported by the Industrial Strategic Technology Development Program (20003968) funded by the Ministry of Trade, Industry \& Energy (MOTIE, Korea). In addition, this work was partially supported by the Brain Korea 21 FOUR project (Education and Research Center for Future Materials).

\section{Author contributions}

J.-S.L. conceived and directed the research. D.L. directed the calculation part. Y.P. performed the experiment and acquired the data. S.H.K. and D.L. performed the firstprinciples calculations. Y.P., S.H.K., D.L., and J.-S.L. wrote the manuscript. Y.P. and S.H.K. contributed equally to this work

\section{Competing interests}

The authors declare no competing interests. 


\section{Additional information}

Supplementary information The online version contains supplementary material available at https://doi.org/10.1038/s41467-021-23871-w.

Correspondence and requests for materials should be addressed to D.L. or J.-S.L.

Peer review information Nature Communications thanks Ho Won Jang and the other, anonymous, reviewer(s) for their contribution to the peer review of this work.

Reprints and permission information is available at http://www.nature.com/reprints

Publisher's note Springer Nature remains neutral with regard to jurisdictional claims in published maps and institutional affiliations. (c) (1) Open Access This article is licensed under a Creative Commons Attribution 4.0 International License, which permits use, sharing, adaptation, distribution and reproduction in any medium or format, as long as you give appropriate credit to the original author(s) and the source, provide a link to the Creative Commons license, and indicate if changes were made. The images or other third party material in this article are included in the article's Creative Commons license, unless indicated otherwise in a credit line to the material. If material is not included in the article's Creative Commons license and your intended use is not permitted by statutory regulation or exceeds the permitted use, you will need to obtain permission directly from the copyright holder. To view a copy of this license, visit http://creativecommons.org/ licenses/by/4.0/.

(C) The Author(s) 2021 